
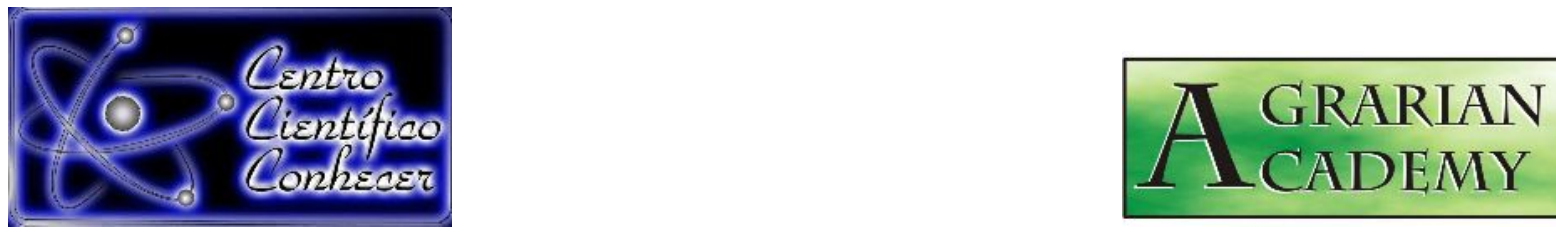

\title{
CARACTERIZAÇÃO DOS FRUTOS E DIVERGÊNCIA GENÉTICA ENTRE ACESSOS DE PASSIFLORA GIBERTII N.E BROWN
}

Angélica Padilha de Freitas ${ }^{1}$, Debora Sarana Ortolan Arantes ${ }^{1}$, Priscila da Silva Salmazo ${ }^{1}$, Leandro Rafael Fachi ${ }^{2^{*}}$, Willian Krause ${ }^{3}$.

${ }^{1}$ Graduandas em Agronomia pela Universidade do Estado de Mato Grosso UNEMAT, Campus de Tangará da Serra, MT, Brasil.

$2^{*}$ Mestre, Pós-graduando em Biotecnologia e Biodiversidade pela Universidade Federal do Mato Grosso UFMT, Campus de Cuiabá, MT, Brasil. e-mail: leandrofachi@hotmail.com

${ }^{3}$ Professor, Doutor em genética da Universidade do Estado de Mato Grosso, Tangará da Serra, MT, Brasil.

Recebido em: 19/11/2018 - Aprovado em: 14/12/2018 - Publicado em: 25/12/2018

DOI: 10.18677/Agrarian_Academy_2018B4

\section{RESUMO}

O Passiflora gibertii N.E Brown tem acenado com contribuições importantes na área do melhoramento genético do maracujazeiro. Contudo, ainda são poucos os relatos na literatura envolvendo a caracterização desses frutos. Além disso, para o melhoramento genético, tal caracterização possui grande importância quando se refere à determinação da variabilidade genética de uma espécie que pode subsidiar programas de melhoramento genético. Deste modo, o objetivo desse trabalho visa a caracterização dos frutos, bem como quantificar a divergência genética entre os acessos de Passiflora gibertii N. E. Brown. Foram avaliados 10 acessos de P. gibertii adotando o delineamento inteiramente casualizado, quatro repetições e cinco frutos por parcela. Foram avaliadas as seguintes características: massa de frutos, comprimento dos frutos, diâmetro dos frutos, formato do fruto, porcentagem de polpa, sólidos solúveis totais, acidez total titulavel, $\mathrm{pH}$ e ratio. Nos acessos avaliados verificou-se a existência variabilidade genética quanto às características físicas e químicas avaliadas, permitindo selecionar plantas com elevado potencial para fins de melhoramento genético, além disso, as características massa de fruto, comprimento do fruto e diâmetro de fruto, são as que mais contribuem para a diversidade genética dos acessos de Passiflora gibertii N.E Brown, constatando que o método UPGMA foi eficiente na estimação da divergência genética da espécie estudada.

PALAVRAS-CHAVE: Melhoramento, silvestre, variabilidade.

\section{CHARACTERIZATION OF FRUITS AND GENETIC DIVERGENCE BETWEEN ACCESSES OF PASSIFLORA GIBERTII N.E BROWN}

\author{
ABSTRACT \\ Passiflora gibertii N.E Brown has waved with important contributions in the area of \\ the genetic improvement of passion fruit. However, there are still few reports in the
}


literature regarding the characterization of these fruits. In addition, for genetic improvement, such characterization is of great importance when it comes to determining the genetic variability of a species that can support genetic breeding programs. Thus, the objective of this work is to characterize the fruits, as well as to quantify the genetic divergence between the accessions of Passiflora gibertii N. E. Brown. Ten accessions of $P$. gibertii were evaluated using a completely randomized design, four replications and five fruits per plot. The following characteristics were evaluated: fruit mass, fruit length, fruit diameter, fruit shape, percentage of pulp, total soluble solids, titratable total acidity, $\mathrm{pH}$ and ratio. In the evaluated accesses, genetic variability was verified regarding the physical and chemical characteristics evaluated, allowing the selection of plants with high potential for genetic improvement, in addition, the characteristics of fruit mass, fruit length and fruit diameter are those that more contribute to the genetic diversity of the accessions of Passiflora gibertii NE Brown, noting that the UPGMA method was efficient in estimating the genetic divergence of the species studied.

KEYWORDS: Improvement, variability, wild.

\section{INTRODUÇÃO}

Algumas espécies silvestres de maracujá têm sido empregadas no melhoramento genético da cultura, no entanto, seu uso tem sido incipiente, devido à existência de poucas informações sobre a diversidade genética disponível. Para que os recursos genéticos do gênero Passiflora sejam utilizados com sucesso, é essencial que sejam realizadas mais pesquisas neste campo com a finalidade de obterem-se mais informações de espécies silvestres (PEREZ et al., 2013; PAIVA et al., 2014; ROSADO et al., 2018).

Neste contexto encontra-se a espécie Passiflora gibertii N.E Brown, a qual é nativa do cerrado brasileiro e conhecida popularmente como maracujá-do-campo (BERNACCl et al., 2013). Esta espécie se destaca por possuir alto valor ornamental, maior longevidade, maior adaptação as condições climáticas adversas, período de florescimento ampliado, maior concentração de componentes químicos de interesse para a indústria farmacêutica e outras potencialidades, quase todas, ainda inexploradas (AGUIAR et al., 2010; CARVALHO et al., 2012).

Esta espécie tem acenado com contribuições importantes ao melhoramento genético uma vez que tem sido apontada como fonte de resistência a algumas doenças importantes para a cultura do maracujazeiro, como a bacteriose (Xanthomonas campestres pv. Passiflorae) e à morte precoce, além de apresentarse tolerante aos fungos Fusarium solani e Phytophtora sp. (RONCATTO et al., 2004; ALVES, 2008; AGUIAR et al., 2010).

Apesar do $P$. gibertii possuir atributos de caracteres fitopatológicos bem difundidos no melhoramento genético, ainda são poucos os relatos na literatura envolvendo a caracterização dos frutos. A caracterização física e química dos frutos permite avaliar as principais propriedades visuais e organolépticas dos frutos, e garantir melhor qualidade e produção. Além disso, para o melhoramento genético, tal caracterização possui grande importância quando se refere à determinação da variabilidade genética de uma espécie que pode subsidiar programas de melhoramento genético (JESUS et al., 2015; FONSECA et al., 2017).

A inserção de espécies silvestres em programas de melhoramento é uma das principais maneiras encontradas para solucionar problemas relacionados a produtividade e adaptabilidade das plantas, visto que essas podem conter genes de 
resistência a doenças e características agronômicas de interesse não encontradas no maracujazeiro cultivado (FALEIRO et al., 2004). Dessa forma, estudar a diversidade genética existente no gênero do maracujá com base em características agronômicas e de interesse para o melhoramento, pois possibilita a identificação de genótipos superiores e contrastantes, indicando possíveis cruzamentos promissores (PAIVA et al., 2014).

Deste modo, o objetivo do presente trabalho visa a caracterização dos frutos de Passiflora gibertii N. E. Brown, bem como a quantificação da divergência genética entre os acessos presentes banco ativo de germoplasma da Universidade do Estado de Mato Grosso, município de Tangará da Serra, MT.

\section{MATERIAL E MÉTODOS}

O trabalho foi realizado na área experimental da Universidade do Estado do Mato Grosso (UNEMAT), campus de Tangará da Serra, MT (14ํㅜㅇ' latitude sul e 572' longitude oeste e altitude de $321 \mathrm{~m}$ ). O clima da região é tropical apresentando estação seca e chuvosa bem definida, a precipitação média anual varia de 1300 a $2000 \mathrm{~mm}^{2} \mathrm{ano}^{-1}$, com uma temperatura anual que varia de 16 a $36^{\circ} \mathrm{C}$ (FENNER et al., 2017).

Foram avaliados 10 acessos de $P$. gibertii do banco ativo de germoplasma presente na área experimental da universidade. O delineamento adotado foi inteiramente casualizado, quatro repetições e cinco frutos por parcela. As características químicas e físicas dos frutos foram avaliadas no período de março a abril de 2018, sendo avaliadas as seguintes características: massa de frutos, comprimento dos frutos, diâmetro dos frutos, formato do fruto, porcentagem de polpa, sólidos solúveis totais, acidez total titulavel, $\mathrm{pH}$ e ratio.

Foi realizada análise de variância pelo teste de Scott Knott. Para quantificar a divergência genética entre os acessos foi empregada a distância Generalizada de Mahalanobis $\left(D^{2}\right)$. Também foi realizada a análise da importância relativa das variáveis pela metodologia de Singh (1981).

O agrupamento dos acessos foi obtido pelo método hierárquico UPGMA (Unweighted Pair-Group Method Using an Arithmetic Average) e a validação foi determinada pelo coeficiente de correlação cofenético. O programa estatístico GENES (CRUZ; GENES, 2013) foi utilizado para a análise de variância, teste de comparação de média, análise da distância genética, estimação do coeficiente de correlação cofenética e da importância dos caracteres. O agrupamento pelo UPGMA foi realizado com o auxílio do programa MEGA versão 5 (KUMAR et al., 2008).

\section{RESULTADOS E DISCUSSÃO}

De acordo com a análise estatística, observou-se que houve diferença significativa a $5 \%$ de probabilidade pelo teste de Scott-Knott para quase todas as características avaliadas, com exceção das características espessura de casca e Ratio (Tabela 1). Essas diferenças indicam a existência de variabilidade genética entre os acessos de $P$. gibertii no banco de germoplasma, podendo ser explorada em programas de melhoramento. 
TABELA 1. Médias das características: massa dos frutos (MF), comprimento de frutos (CF), diâmetro de frutos (DF), formato do fruto (FF) espessura de casca (EC), porcentagem de polpa (PP), potencial hidrogeniônico $(\mathrm{pH})$, teor de sólidos solúveis (SST), acidez total titulável (ATT) e ratio, proveniente dos 10 acessos de $P$. gibertii.

\begin{tabular}{|c|c|c|c|c|c|c|c|c|c|c|}
\hline Acesso & $\begin{array}{c}\mathrm{MF} \\
\mathrm{g}\end{array}$ & $\begin{array}{c}\text { CF } \\
----\end{array}$ & $\begin{array}{r}\text { DF } \\
\text { n---- }\end{array}$ & $\begin{array}{c}\text { FF } \\
(\mathrm{CF} / \mathrm{DF})\end{array}$ & $\begin{array}{l}\mathrm{EC} \\
\mathrm{mm}\end{array}$ & $\begin{array}{l}\text { PP } \\
\% \\
\end{array}$ & $\mathrm{pH}$ & $\begin{array}{l}\text { SST } \\
\text { oBrix }\end{array}$ & $\begin{array}{c}\text { ATT } \\
\% \\
\end{array}$ & Ratio \\
\hline 1 & $6,91 a^{*}$ & $4,13 a$ & $3,53 a$ & $1,17 b$ & $0,17 \mathrm{a}$ & $38,32 b$ & $5,86 \mathrm{~b}$ & $6,22 \mathrm{a}$ & $7,94 \mathrm{a}$ & $0,78 \mathrm{a}$ \\
\hline 2 & $4,37 \mathrm{c}$ & $3,91 \mathrm{~b}$ & $3,26 \mathrm{c}$ & $1,19 b$ & $0,15 a$ & $42,34 \mathrm{~b}$ & $6,16 \mathrm{a}$ & $5,00 \mathrm{~b}$ & $6,03 \mathrm{~b}$ & $0,88 \mathrm{a}$ \\
\hline 3 & $4,30 \mathrm{c}$ & $3,54 \mathrm{c}$ & $3,03 \mathrm{~d}$ & $1,16 b$ & $0,17 \mathrm{a}$ & $45,03 b$ & $6,18 \mathrm{a}$ & $5,12 b$ & $6,17 b$ & $0,84 \mathrm{a}$ \\
\hline 4 & $5,47 \mathrm{~b}$ & $4,09 a$ & $3,43 \mathrm{~b}$ & $1,19 b$ & $0,19 a$ & $41,24 \mathrm{~b}$ & $5,87 \mathrm{~b}$ & $4,90 \mathrm{~b}$ & $5,59 b$ & $0,88 \mathrm{a}$ \\
\hline 5 & $4,47 \mathrm{c}$ & $3,87 b$ & $2,99 d$ & $1,29 a$ & $0,18 a$ & $51,81 \mathrm{a}$ & $5,83 \mathrm{~b}$ & $4,47 \mathrm{~b}$ & $5,67 \mathrm{~b}$ & $0,81 \mathrm{a}$ \\
\hline 7 & $3,55 \mathrm{c}$ & $3,90 \mathrm{~b}$ & $3,10 \mathrm{~d}$ & $1,26 \mathrm{a}$ & $0,16 \mathrm{a}$ & $32,71 \mathrm{~b}$ & $5,89 \mathrm{~b}$ & $5,17 \mathrm{~b}$ & $5,60 \mathrm{~b}$ & $0,92 \mathrm{a}$ \\
\hline 8 & $4,95 \mathrm{~b}$ & $4,02 \mathrm{~b}$ & $3,33 \mathrm{c}$ & $1,20 \mathrm{~b}$ & $0,16 \mathrm{a}$ & $45,26 \mathrm{~b}$ & $6,23 \mathrm{a}$ & $5,67 \mathrm{~b}$ & $6,09 \mathrm{~b}$ & $0,93 \mathrm{a}$ \\
\hline 9 & $6,25 a$ & $4,35 \mathrm{a}$ & $3,61 \mathrm{a}$ & $1,20 \mathrm{~b}$ & $0,16 \mathrm{a}$ & $38,79 \mathrm{~b}$ & $6,20 \mathrm{a}$ & $5,47 b$ & $6,89 a$ & $0,79 a$ \\
\hline 10 & $6,62 \mathrm{a}$ & $4,25 \mathrm{a}$ & $3,73 a$ & $1,14 \mathrm{~b}$ & $0,18 \mathrm{a}$ & $43,05 \mathrm{~b}$ & $5,90 \mathrm{~b}$ & $6,30 \mathrm{a}$ & $7,38 \mathrm{a}$ & $0,85 \mathrm{a}$ \\
\hline
\end{tabular}

*Médias seguidas da mesma letra na coluna, não diferem estatisticamente entre si pelo teste de Scott-Knott, à $5 \%$ de probabilidade. 
Verificou-se que os acessos apresentaram uma grande variação em relação a massa dos frutos $(6,97$ à $3,55 \mathrm{~g})$, sendo os acessos $1 ; 6 ; 9$ e 10 os que apresentaram as melhores médias $(6,91 ; 6,97 ; 6,25$ e 6,62 g). Consequentemente os acessos $1 ; 6 ; 9$ e 10 apresentaram os maiores comprimentos $(4,13 ; 4,49 ; 4,35$ e $4,25 \mathrm{~cm})$ e diâmetro dos frutos $(3,53 ; 3,71 ; 3,61$ e 3,73). Resultados semelhantes foram obtidos por Gottardo et al., (2015), ao caracterizarem a qualidade físicoquímica de frutos de $P$. gibertii encontraram massa média de 6,26 g. Contudo, os mesmos autores encontraram diâmetro $(2,88 \mathrm{~cm})$ e comprimento $(3,11 \mathrm{~cm})$ inferiores a esse trabalho, consequência de um longo período de seca que ocorreu na região.

Em relação a qualidade química dos frutos, os acessos 1; 6 e 10 apresentaram as maiores médias encontradas para sólido solúveis totais $(6,22,6,30$ e 6,62 ${ }^{\circ}$ Brix). Enquanto que na acidez total titulável os melhores resultados foram obtidos nos acessos 1, 9 e 10 (7,94, 6,89 e 7,38). Nos padrões de qualidade química dos frutos do maracujá amarelo (Passiflora edulis spp) o ${ }^{\circ}$ brix é um dos principais parâmetros utilizados como indicador na qualidade dos frutos que são destinados à industrialização, havendo preferência por frutos mais doces e menos ácidos com teores de sólidos solúveis superiores a 13Brix (SANTOS et al., 2017). Contudo, tais padrões não se aplicam aos frutos de $P$. gibertii, pois tal espécie é utilizada principalmente como planta ornamental não apresentando frutos de interesse comercial (CAVICHIOLI et al., 2014; GOTTARDO et al., 2015).

Utilizada principalmente como planta ornamental, o $P$. gibertii não apresenta frutos de interesse comercial, contudo, a caracterização física e química dos frutos é de fundamental importância em trabalhos de melhoramento genético de espécies de maracujá, pois torna-se possível realizar uma comparação com os frutos do maracujá amarelo visando futuros cruzamentos (SALAZAR et al., 2015; FRANCA et al., 2018). A exemplo disso, destaca-se a alta produção de flores do $P$. gibertii, (10 a 30 flores por dia) gerando por consequência um grande número de frutos, tornandose uma alternativa para o melhoramento do maracujazeiro, afim de aumentar o número de flores e frutos em cultivares comerciais (VANDERPLANK, 2000).

$\mathrm{Na}$ figura 1 está apresentada a análise de agrupamento obtido pelo método UPGMA, observa-se a formação de dois grandes grupos. O grupo I, constituído por dois subgrupos: acessos 1, 9, 10 e 6 e o acesso 4 sozinho no outro subgrupo. Já o grupo II, formado pelos subgrupos: acessos 5 e 7 e acessos 2, 3 e 8 . Nesse sentido percebe-se que o grupo I apresenta como peculiaridade ser formado pelos acessos que apresentaram valores médios superiores nas características físicas dos frutos, enquanto o grupo II por sua vez foi formado pelos acessos que apresentaram características químicas mais elevadas (Tabela 1).

De acordo com Cavalcante et al. (2016) para o melhoramento genético do maracujazeiro, tal resultado apresenta grande importância em processos de hibridação, pois permite selecionar os acessos de acordo com a necessidade do mercado que se pretende trabalhar. Além disso, frutos destinados ao consumo in natura devem apresentam características bem definidas, como: tamanho grande que garanta a classificação comercial adequada aos padrões do mercado, coloração uniforme, boa aparência, resistência ao transporte e boa conservação pós-colheita; enquanto para a agroindústria, os frutos precisam apresentar elevado rendimento de suco, acidez total titulável e teor de sólidos solúveis totais elevados (OLIVEIRA et al., 1994). 


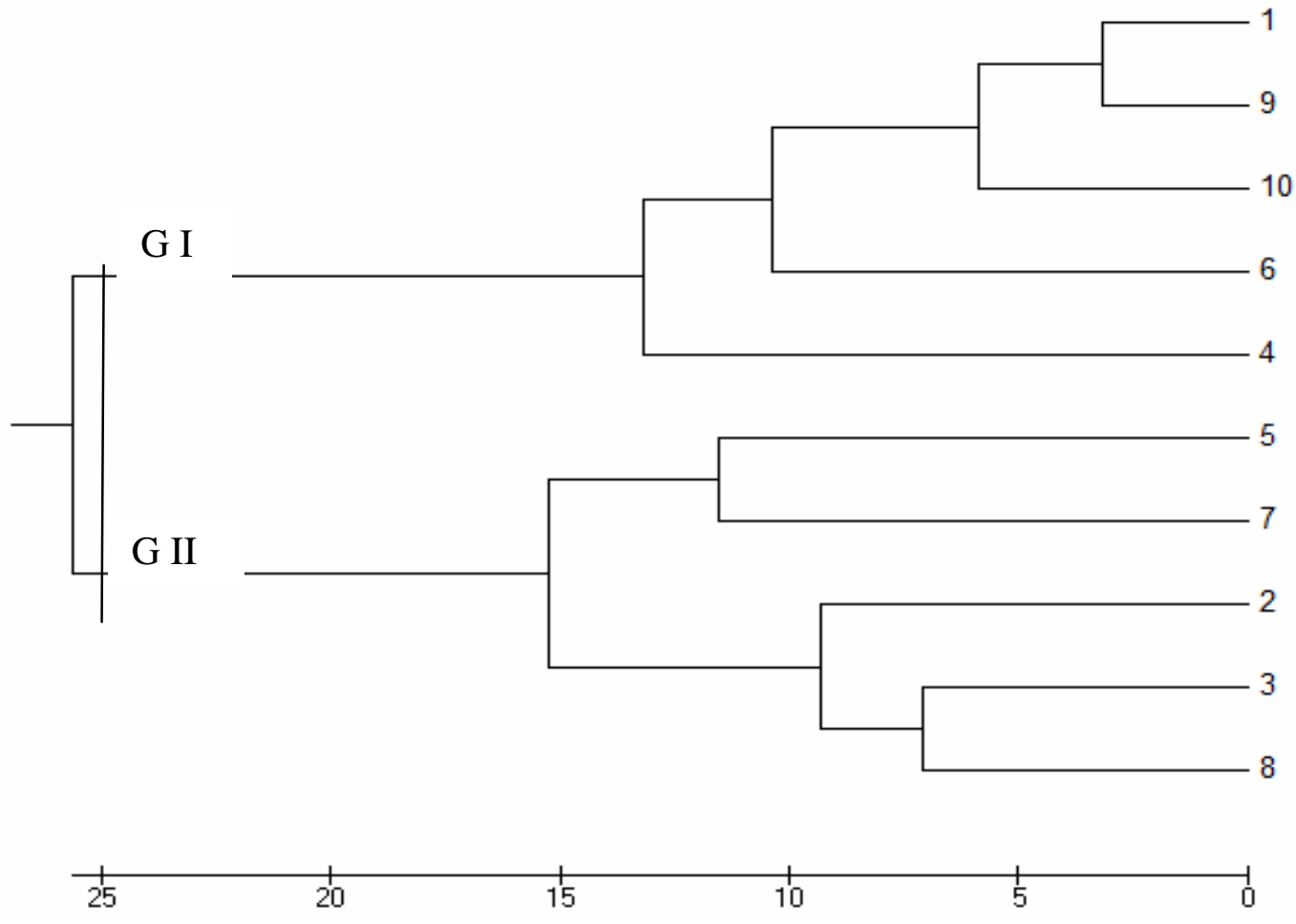

FIGURA 1. Análise de agrupamento de 10 acessos de $P$. gibertii, obtido pelo método UPGMA, com base em 10 características físicas e químicas dos frutos. Os números correspondem aos acessos de $P$. gibertii.

Também foi realizada a análise de dispersão gráfica baseada nas variáveis canônicas (VC) foi verificado que as duas primeiras variáveis foram responsáveis por $74,12 \%$, sendo VC1 responsável por 58,82\% e VC2 por 15,30\% (Figura 1). Logo, um gráfico bidimensional capitaliza uma boa proporção da variabilidade total responsável pela variação total. Como a análise é comparativa entre os acessos estudados, as distâncias gráficas entre tais acessos ilustram as distâncias genéticas entre eles, permitindo melhor compreensão dos resultados. 


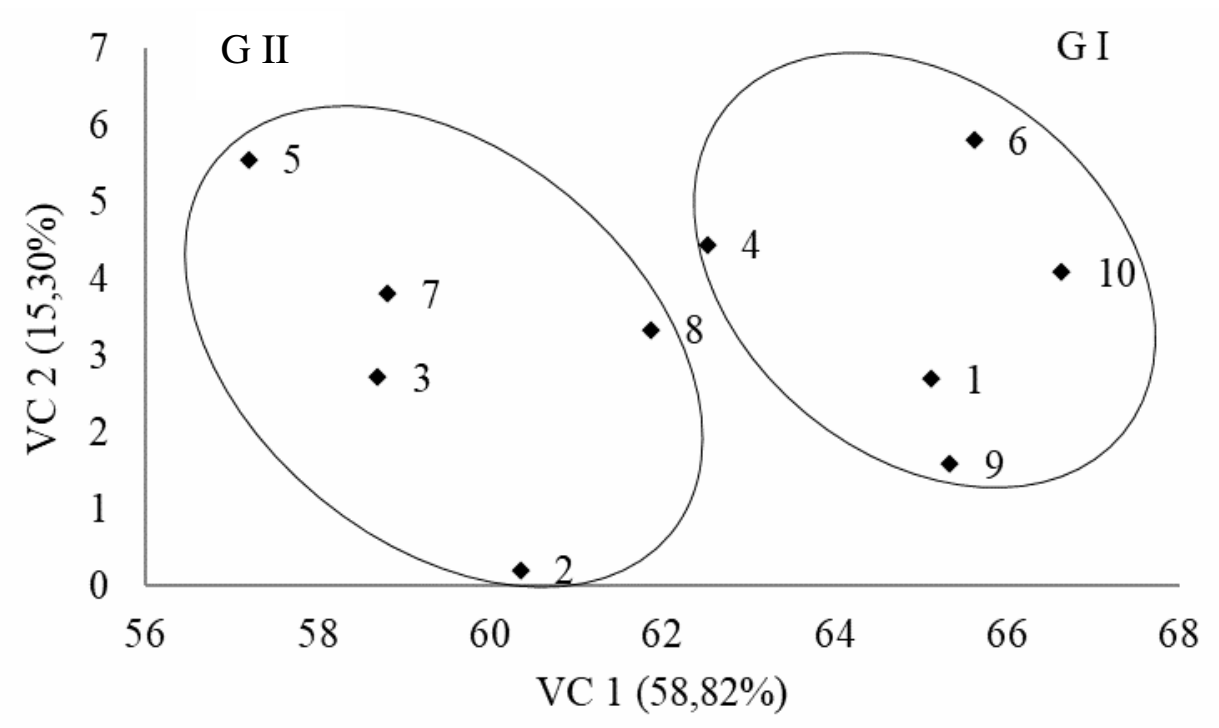

FIGURA 2. Dispersão das duas primeiras variáveis canônicas (VC1 e VC2) representando a formação de dois grupos pela estratégia UPGMA, com base na avaliação de 10 características físicas e químicas dos frutos de $P$. gibertii.

A tabela 2 demonstra a contribuição relativa de características físicas e químicas do fruto para a estimação da diversidade. Verificaram-se as características massa de fruto $(10,85 \%)$, comprimento do fruto $(22,99 \%)$ e diâmetro de fruto $(38,53 \%)$, foram as características que mais contribuíram para a divergência total. Tais características proporcionaram maiores contribuições pois se tratam de frutos e características como tamanho e forma que se destacaram na diferenciação de espécies e cultivares de maracujazeiro (MELETTI et al., 2003; ASSUNÇÃO et al., 2015).

TABELA 2. Contribuição relativa de 10 características físicas e químicas do fruto para a diversidade, baseada na Distância Generalizada de Mahalanobis entre 10 acessos de P. gibertii. Tangará da Serra - MT, 2018.

\begin{tabular}{ccc}
\hline Características avaliadas $^{1 /}$ & $\mathrm{S}^{1}$ & Contribuição \% $^{1}$ \\
MF & 467,957263 & 10,8531 \\
PP & 162,16668 & 3,7611 \\
CF & 991,681287 & 22,9997 \\
DF & 1661,507446 & 38,5347 \\
FF & 64,32911 & 1,492 \\
EC & 78,426964 & 1,8189 \\
PH & 90,868201 & 2,1075 \\
SST & 496,550266 & 11,5163 \\
ATT & 2,056873 & 0,0477 \\
RAT & 296,17778 & 6,8691
\end{tabular}

${ }^{1 /}$ Massa de fruto (MF), porcentagem de polpa (PP), comprimento do fruto (CF), diâmetro de fruto (DF), formato de fruto (FF), espessura de casca (EC), pH, teor de sólidos solúvel totais (SST), acidez total titulável (ATT), Ratio (RAT). 'Diversidade (Sj). 
De acordo com Machado et al. (2015), a espécies $P$. gibertii demonstra potencial de uso em programas de melhoramento genético de maracujazeiro, possuindo ampla variabilidade genética existente dentro da espécie. Além disso, a ampla variabilidade genética verificada nos acessos de $P$. gibertii pode ser uma ferramenta promissora para a realização de cruzamentos interespecíficos com espécies comerciais, permitindo ao melhorista incorporar os genótipos comerciais alelos favoráveis encontrados em espécies silvestres como, por exemplo, resistência a doenças, autocompatibilidade e melhoria da qualidade física e química dos frutos comerciais (PAIVA et al., 2014).

\section{CONCLUSÃO}

Nos acessos avaliados verificou-se a existência variabilidade genética quanto às características físicas e químicas avaliadas, permitindo selecionar plantas com elevado potencial para fins de melhoramento genético;

Existe divergências genéticas entre os acessos de Passiflora gibertii N.E Brown estudadas nesse trabalho, promovendo a formação de grupos diferentes pelo método UPGMA;

As características massa de fruto, comprimento do fruto e diâmetro de fruto, são as que mais contribuem para a diversidade genética dos acessos de Passiflora gibertii N.E Brown;

\section{REFERÊNCIAS}

ALVES, A. C. C. N. Passion flower littleleaf mosaic begomovirus: Reação de espécies de Passiflora, gama parcial de hospedeiros, seleção de estirpe fraca e transmissão por Bemisia tabaci biótipo B. 2008. 48 f. Dissertação (Mestrado em agronomia) Escola Superior Agrícola Luiz de Queiroz, Piracicaba -SP, 2008.

AGUIAR, A. V.; SILVA, R. M.; CARDOSO, E. A.; MARAJÁ, P. B.; PIRES, H. G. Utilização de espécies de Passiflora spp. como porta-enxertos no controle de doenças do maracujazeiro. Agropecuária Científica no Semi-Árido, v. 6, n. 4, p. 17-22, 2010.

ASSUNÇÃO, M. P.; KRAUSE, W.; DALLACORT, R.; SANTOS, P. R. J.; NEVES, L. G. Seleção individual de plantas de maracujazeiro azedo quanto à qualidade de frutos via reml/blup. Revista Caatinga, v. 28, p. 57-63, 2015. Disponível em: < https://periodicos.ufersa.edu.br/index.php/caatinga/article/view/4075/pdf_246>.

BERNACCI, L. C.; CERVI, A. C.; MILWARD-DE-AZEVEDO, M. A.; NUNES, T. S.; IMIG, D. C. et al. Passifloraceae. In: Lista de espécies da flora do Brasil. Jardim Botânico do Rio de Janeiro. 2013. Disponível em: <http://www.floradobrasil.jbrj. gov.br/jabot/floradobrasil/FB12506>.

CARVALHO, M. A. F.; PAIVA, R.; VARGAS, D. P.; PORTO, J. M. P.; HERRERA, R. C. et al. Germinação in vitro de Passiflora gibertii N. E. Brown com escarificação mecânica e ácido giberélico. Semina: Ciências Agrárias, v. 33, n. 3, p.1027-1032, 2012. Disponível em: <http://dx.doi.org/10.5433/1679-0359.2012v33n3p1027>. 
CAVALCANTE, N. R.; KRAUSE, W.; CARVALHO, J. F.; ROCHA, M. K. P.; PALÚ, E. G. et al. Productivity, fruit physicochemical quality and distinctiveness of passion fruit populations. Revista Brasileira de Fruticultura, v. 38, p. e-142, 2016. Disponível em: $<$ http://www.scielo.br/scielo.php?script=sci_arttext\&pid=S0100$29452016000400801 \quad \& \operatorname{lng}=e n \& n r m=i s o>$. doi: https://dx.doi.org/10.1590/010029452016142.

CAVICHIOLI, J. C.; KASAI, F. S.; NASSER, M. D. Productivity and physical characteristics of fruits of Passiflora edulis grafted Passiflora gibertii in different planting densities. Revista Brasileira de Fruticultura, v. 36, p. 243-247 2014. Disponível em: <http://www.scielo.br/scielo.php?script=sci_arttext\&pid=S010029452 014000100029\&Ing=en\&nrm=iso>. doi: http://dx.doi.org/10.1590/0100-2945$238 / 13$.

CRUZ, C. D. GENES - a software package for analysis in experimental statistics and quantitative genetics. Acta Scientiarum. v. 35, n. 3, p. 271-276, 2013.

FALEIRO, F. G.; JUNQUEIRA, N. T. V.; BELLON, G.; BORGES, T. A.; ANJOS, J. R. N.; PEIXOTO, J. R. et al. Diversidade genética de espécies silvestres de maracujazeiro com resistência a múltiplas doenças com base em marcadores RAPD. Fitopatologia Brasileira, v. 29, supl, p. S325, 2004.

FENNER, W.; DALLACORT, R.; SILVA, S. F.; NEVES, S. M. A. S.; BARBIERI, J. D. et al. Zoneamento do índice de satisfação de exigências hídricas para o feijoeiro em Mato Grosso. Revista Brasileira Engenharia Agrícola Ambiental. V, 21, n. 7, 2017. Disponível em: <http://dx.doi.org/10.1590/1807-1929/agriambi. v21n7p476480>.

FRANÇA, J. M.; VENIAL, L. R.; COSTA, E. B.; SCHMILDT, E. R.; SCHMILDT, O. et al. Morphophysiology, Phenotypic and Molecular Diversity of Auxin-induced Passiflora mucronata Lam. (Passifloraceae). In: Anais da Academia Brasileira de Ciências, v. 90, n. 2, p. 1799-1814, 2018. doi:https://dx.doi.org/10.1590/00013765201820160898.

FONSECA, K. G.; GELAPE, F. F.; JUNQUEIRA, N. T. V.; BARTH, M.; FELDBERG, N. P. Morphoagronomic and molecular characterization of ornamental passion fruit cultivars. Pesquisa Agropecuária Brasileira, v. 52, n. 10, p. 849-860, 2017. Disponível em: <https://dx.doi.org/10.1590/s0100-204x2017001000004>.

GOTTARDO, L. E.; VENTURA, I. J. O.; COELHO, M. B.; PRANDO, J. F.; OLIVEIRA, V. S. et al. Caracterização físico-química de frutos de Passiflora gibertii N. E. Brown. In: VIII Congresso Brasileiro de Melhoramento de Plantas, n. 8, 2015, Goiânia, 2015.

JESUS, O. N.; OLIVEIRA, E. J.; SOARES, T. L.; FALEIRO, F. G. Aplicação de descritores morfoagronômicos utilizados em ensaios de DHE de cultivares de maracujazeiro-doce, ornamental, medicinal, incluindo espécies silvestres e híbridos interespecíficos (Passiflora spp.): manual prático. Brasília: Embrapa, 2015. 45p. 
KUMAR, S.; DUDLEY, J.; NEI, M.; TAMURA, K. MEGA: A biologist-centric software for evolutionary analysis of DNA and protein sequences. Briefings in Bioinformatics, Oxford, v. 9, p. 299-306, 2008.

MACHADO, C. F.; JESUS, F. N.; LEDO, C. A. S. Divergência genética de acessos de maracujá utilizando descritores quantitativos e qualitativos. Revista Brasileira de Fruticultura, v. $37, \quad$ n. $2, \quad$ p. 442-449, 2015. Disponível em: < https://www.alice.cnptia.embrapa.br/alice/bitstream/doc/1028495/1/DIVERGENCIAG ENETICA.pdf>. doi: http://dx.doi.org/10.1590/0100-2945-110/14.

MELETTI, L. M. M.; BERNACCI, L. C.; SOARES-SCOTT, M. D.; AZEVEDO FILHO, J. A.; MARTINS, A. L. M. Variabilidade genética em caracteres morfológicos, agronômicos e citogenéticos de populações de maracujazeiro-doce (Passiflora alata Curtis). Revista Brasileira de Fruticultura, v. 25, n. 2, p. 275-278, 2003. Disponível em: < http://www.scielo.br/scielo.php?script=sci_arttext\&pid=S0100-29452003000 200023\&lng=en\&nrm=iso >. doi:https://dx.doi.org/10.1590/S0100-29452003000200 023.

OLIVEIRA, J. C.; NAKAMURA, K.; MAURO, A. O.; CENTURION, M. A. P. C. Aspectos gerais do melhoramento do maracujazeiro. In: São José, A.R. Maracujá: produção e mercado. Vitória da conquista, Ba: Universidade Estadual do Sudoeste da Bahia - UESB, p. 27-37, 1994.

PAIVA, C. L.; VIANA, A. P.; SANTOS, E. A.; SILVA, R. N. O.; OLIVEIRA, E. J. Diversidade genética de espécies do gênero Passiflora com o uso da estratégia WARD-MLM. Revista Brasileira de Fruticultura, v.36, p.381-390, 2014. Disponível em: < http://www.alice.cnptia.embrapa.br/alice/handle/doc/1005758>.

PÉREZ, J. O.; URREA, R.; WYCKHUYS, K.; SALAZAR, M. Exploración de la variabilidad genética del maracuyá (Passiflora edulis $f$. flavicarpa Degener) como base para un programa de fitomejoramiento en Colombia. Acta Agronómica, v. 62, n. 4, p. 352 - 360, 2013. Disponível em: <https://revistas.unal.edu.co/index.php/acta_ agronomica/article/view/33858>.

RONCATTO, G.; OLIVEIRA, J. C.; RUGGIERO, C.; FILHO, G. C. N.; CENTURION, M. A. P. C. et al. Comportamento de maracujazeiros (Passiflora spp.) quanto à morte prematura. Revista Brasileira de Fruticultura, v. 26, n. 3, p 552-554, 2004. Disponível em: < http://www.scielo.br/pdf/rbf/v26n3/23168.pdf>.

ROSADO, R. D., ROSADO, L. D., BORGES, L. L., BRUCKNER, C. H., CRUZ, C. D. et al. Genetic diversity of sour passion fruit revealed by predicted genetic values. Agronomy Journal. 2018. doi:10.2134/agronj2018.05.0310.

SALAZAR, A. H.; SILVA, D. F. P.; SEDIYAMA, C. S.; BRUCKNER, C. H. Caracterização física e química de frutos de maracujazeiro-amarelo enxertado em espécies silvestres do gênero passiflora cultivado em ambiente protegido. Revista Brasileira de Fruticultura, v. 37, n. 3, p. 635-643, 2015. Disponível em: < http://www.scielo.br/scielo.php?script=sci_arttext\&pid=S0100-29452015000300635\& Ing=en\&nrm=iso >. doi: https://dx.doi.org/10.1590/0100-2945-101/14.

AGRARIAN ACADEMY, Centro Científico Conhecer - Goiânia, v.5, n.10; p. 382018 
SANTOS, V. A.; RAMOS, J. D.; LAREDO, R. R.; SILVA, F. O. R.; CHAGAS, E. A. Produção e qualidade de frutos de maracujazeiro-amarelo provenientes do cultivo com mudas em diferentes idades. Revista de Ciências Agroveterinárias, v. 16, n. 1, p. 33-40, 2017. Disponível em: < http://revistas.udesc.br/index.php/agroveterinaria/ article/viewFile/223811711612017033/pdf>. doi:10.5965/223811711612017033.

SINGH, D. The relative importance of characters affecting genetic divergence. Indian Journal of Genetic and Plant Breeding, New Delhi, v. 41, n. 2, p. 237-245, 1981.

VANDERPLANK, J. Passion flowers. $3^{\mathrm{a}}$ ed. Cambridge: The MIT Press, 2000. 224 p. 